\title{
An improved method to monitor the health of seagrass meadows based on kriging
}

\author{
Agathe Leriche $^{\mathrm{a}, *, 1}$, Charles-François Boudouresque ${ }^{\mathrm{a}}$, Pascal Monestiez ${ }^{\mathrm{b}}$, Vanina Pasqualini ${ }^{\mathrm{c}}$ \\ a Mediterranean Institute of Oceanography, Campus Universitaire de Luminy, 13288 Marseille cedex 9, France \\ b INRA, Biostatistique et Processus Spatiaux, Domaine St Paul, Site Agroparc, 84914 Avignon cedex 9, France

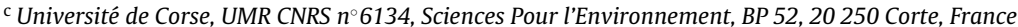

Keywords:

Shoot density

Depth

Monitoring

Mapping

Posidonia oceanica

Mediterranean

\begin{abstract}
A B S T R A C T
This paper focuses on the spatial pattern of the shoot density of the seagrass Posidonia oceanica through kriging methods. Kriging is a group of geostatistical techniques to predict the value of a field at an unobserved location from observations of its value at nearby locations. The results of an ordinary kriging of both raw values of shoot density and normalized shoot density with reference to a density vs. depth model (Dn) were compared. Results confirmed the existence of spatially organized parameters other than depth that influence patterns of $P$. oceanica shoot density. Although still requiring additional testing for complete validation, Dn mapping appears to be a valuable tool to (1) infer causes for the meadow's condition and to design a cost-effective field survey; (2) define areas where protection policies should be undertaken.
\end{abstract}

\section{Introduction}

Seagrass meadows are considered amongst the most important marine ecosystems, from the points of view of biodiversity, ecology and economics (Duffy, 2006). For this reason and for coastal management purposes, a significant effort has been devoted worldwide to the mapping of seagrass meadows (e.g. Frederiksen et al., 2004a; Leriche et al., 2004; Fornes et al., 2006; Pergent-Martini et al., 2006). Most of these maps only deal with the spatial extent of the meadows and do not provide information about the health of the Posidonia oceanica meadow, in contrast with maps including qualitative and quantitative data (e.g. healthy beds vs. those in bad condition, expansion vs. regression trend, continuous vs. patchy beds, dense vs. sparse and ecological indices addressing the bed's health) (Pasqualini et al., 1999; Ward et al., 2003; Frederiksen et al., 2004b; Garono et al., 2004; Montefalcone et al., 2006).

Kriging is a group of geostatistical techniques based on stochastic modelling and a linear interpolator used to predict the value of a field at an unobserved location from observations of its value at nearby locations. This technique provides a detailed description

\footnotetext{
* Corresponding author. Tel.: +33 4 42908455; fax: +33 442908448 .

E-mail address: agathe.leriche@univ-cezanne.fr (A. Leriche).

1 Present address: Université d'Aix-Marseille 3, IMEP, CNRS UMR 6116, BP 80, 13545 Aix-en-Provence, France.
}

of the structural characteristics of natural systems (Cressie, 1991). The first map of $P$. oceanica shoot density, interpolated via kriging from raw data, was presented by Scardi et al. (1989) and new maps were produced in the following years (Pergent, 1990; Pergent et al., 1995a; Scardi et al., 2006; Zupo et al., 2006a,b). Shoot density changes occur in $P$. oceanica beds, both in time and in space (Panayotidis et al., 1981; Borg et al., 2006; Zupo et al., 2006a,b). The decrease in density with depth is a general feature of $P$. oceanica meadows (Augier and Boudouresque, 1973; Panayotidis et al., 1981; Pergent and Pergent-Martini, 1988) related to the decline of irradiance and temperature along the depth gradient (Pirc, 1984; Zimmerman et al., 1994; Ruiz and Romero, 2001). Pergent et al. (1995b) and Pergent-Martini et al. (1999) studied the variations of $P$. oceanica shoot density with depth on 400 sites across the western Mediterranean Sea. They found that depth explained $54 \%$ of the spatial variation in shoot density. The model they fit to shoot density measurements in relation with depth can be used to assess if shoot density measured at a given depth is low, normal or high. Most Mediterranean laboratories use this standardized scale of evaluation. According to many authors (Pergent et al., 1995b; Buia et al., 2000; Ruiz and Romero, 2001; Gobert et al., 2003), other parameters explaining shoot density variability could be water turbidity, pollution, water movement, substratum typology and plant stonolization pattern, but no analyses or data have been provided to support the hypothesis of the influence of spatially structured factors on shoot density patterns. 
The aim of this paper is to present a method for analysing spatial seagrass shoot density distribution eliminating the depth effect that masks other pattern of ecological relevance. To determine if there is residual non-random spatial structure after the effect of depth on shoot density has been accounted for, two interpolated maps of the raw and normalized shoot density of a Mediterranean $P$. oceanica meadow were developed and compared.

\section{Methods}

\subsection{Study area}

The study area (Saint-Cyr Bay; approximately $4 \mathrm{~km}^{2}$ ) is located to the east of Marseilles (Provence, France; $43^{\circ} 10^{\prime} \mathrm{N}-5^{\circ} 41^{\prime} \mathrm{E}$ ). The $P$. oceanica meadow occupies a wide depth range (from a few meters down to $33 \mathrm{~m}$ deep) for a surface area of approximately $195 \mathrm{ha}$. $P$. oceanica grows mostly on sandy substrate with the exception of two rocky areas (Saint-Louis Cape and La Madrague harbour). Human impact at the study site originates from the port facilities of La Ciotat (5 km westwards), two small pleasure boat harbours, coastal leisure activities, trawling and a pipe discharging treated sewage at depth of $40-50 \mathrm{~m}$ (23,000 population-equivalent). Such impacts may lead to the appearance of dead matte areas (dead matte is constituted by the intertwined dead rhizomes the interstices of which are filled with sediment). The meadow's upper and lower depth limits and areas without $P$. oceanica (intermattes) were mapped in a GIS (Geographic Information System) software ArcView 3.2 ${ }^{\circledR}$, using methods detailed in Leriche et al. (2006).

\subsection{Measuring the shoot density}

The shoot density is the mean number of living $P$. oceanica shoots per unit surface area. Only bottom areas occupied by the meadow are taken into consideration. Measurement of shoot density was performed on 34 sites; most of these sites are located along transects (T1 through T5). Sampling design was defined to cover the meadow and environmental conditions in the area as uniformly as possible, with transects crossing the meadow from deep to shallow limits, on sandy and rocky substratum. Five counts were performed within $20 \mathrm{~cm} \times 20 \mathrm{~cm}$ plots at each sampling point at all sites but one (three counts). This protocol follows recommendations found in the literature (Marcos-Diego et al., 2000; Pergent-Martini et al., 2005). It is also similar to the protocol applied by Pergent et al. (1995b) and Pergent-Martini et al. (1999) to collect the data used to generate the regression model of shoot density with depth which was used in the present study. Shoot density was expressed in number of shoots per square meter. The 34-site median standard deviation of the measurements was of 53 shoots per square meter. For each site, the measurements were averaged to give the "raw" shoot density value of the site.

\subsection{Raw shoot density kriging}

The steps in the kriging process are (1) build a semi-variogram from observed data (experimental semi-variogram) corresponding to the semivariance of value differences in relation to spatial distance between sites; (2) fit a function (theoretical semi-variogram) to the experimental semi-variogram, using one or more specific models (spherical, exponential, etc.); (3) from the theoretical semivariogram build the kriging system; (4) solve it to get the optimal weights for the linear interpolator.

Several anisotropic (i.e. direction dependant) theoretical semivariogram models were performed, fitted by least squares regression of the experimental semi-variogram that was computed on raw data (average of the five measurements taken at a site, expressed per square meter) by means of Geostatistical Analyst ${ }^{\circledR}$
Table 1

Values of the parameters of semi-variogram fitting; sill: limit of the semi-variogram tending to infinity; nugget value: the semivariogram discontinuity at the origin; range: the distance in which the semi-variogram reaches the sill. Due to the anisotropy both a major range with its direction and minor range (orthogonal to major direction) are indicated.

\begin{tabular}{lll}
\hline & $\begin{array}{l}\text { Ordinary kriging on raw } \\
\text { data of shoot density }\end{array}$ & $\begin{array}{l}\text { Ordinary kriging on } \\
\text { normalized shoot density (Dn) }\end{array}$ \\
\hline Major range & $2420 \mathrm{~m}$ & $2420 \mathrm{~m}$ \\
Direction & $350^{\circ}$ & $350^{\circ}$ \\
Minor range & $1145 \mathrm{~m}$ & $1015 \mathrm{~m}$ \\
Nugget & 0.00 & 0.01 \\
Sill & 84,800 & 1.79 \\
\hline
\end{tabular}

(extension of Arcview 8.3 ${ }^{\circledR}$ ). The best fitted model (validated by scatter plots of predicted values by cross-validation vs. true values) was a classical spherical semi-variogram (Webster et al., 2007), and characterized by a small number of parameters. No nugget effect (discontinuity at the origin representing non-spatial pure random effect) was included, which is consistent with the shoot density kriging calibration found in the literature (e.g. Zupo et al., 2006a). An ordinary kriging of raw data, that assumes stationarity with a constant but unknown mean (Cressie, 1991; Webster et al., 2007) was then performed with the same software.

\subsection{Normalized shoot density modelling and kriging}

The regression of shoot density with depth in relatively undisturbed sites could be modelled as:

$y=-254 \ln (x)+1045.8$ with $s d=112$

where $y$ is the shoot density (number $\mathrm{m}^{-2}$ ), $x$ is the depth ( $\mathrm{m}$ ) and $s d$ is the standard deviation of the curve from Pergent et al. (1995b) and Pergent-Martini et al. (1999).

In order to remove the effect of depth on P. oceanica shoot density values, the normalized density (Dn), i.e. the deviation from the theoretical mean density (reference level) at a given depth, was calculated. This has been done for each studied site in Arcview 8.3 ${ }^{\circledR}$ database with the equation:

Dn $=\frac{(D-[-254 \ln (x)+1045.8])}{s d}$

where $\mathrm{Dn}$ is the normalized shoot density at a site, $D$ is the mean of the five measurements of shoot density taken at a site in the study area and $x$ is depth of the site.

Because the anisotropy still remains, the geostatistical procedure applied on normalized data was the same as on raw data. Five classes were considered: medium density (variance from the mean $<|0.1|$, meaning value of shoot density close to the value expected from the model of density variation with depth), low and high $(|0.1|<$ variance from the mean $<|0.5|)$ and very low and very high (variance from the mean $>|0.5|$ ).

\section{Results}

Parameters of the semi-variogram fitted on both raw and normalized shoot density data are presented in Table 1. A semivariogram presents a flat region where the semivariance no longer increases. The distance where the model first flattens out is known as the range ( $x$-axis) and the value at which the semivariogram model attains the range ( $y$-axis) is called the sill. In this study, because of anisotropy the "range" characteristics are given through three parameters: a major range with its direction and a minor range on the orthogonal direction. Except for the sill, which models data variance, parameters for raw and normalized shoot density data are very close. The nugget values (i.e. height of the jump of the 


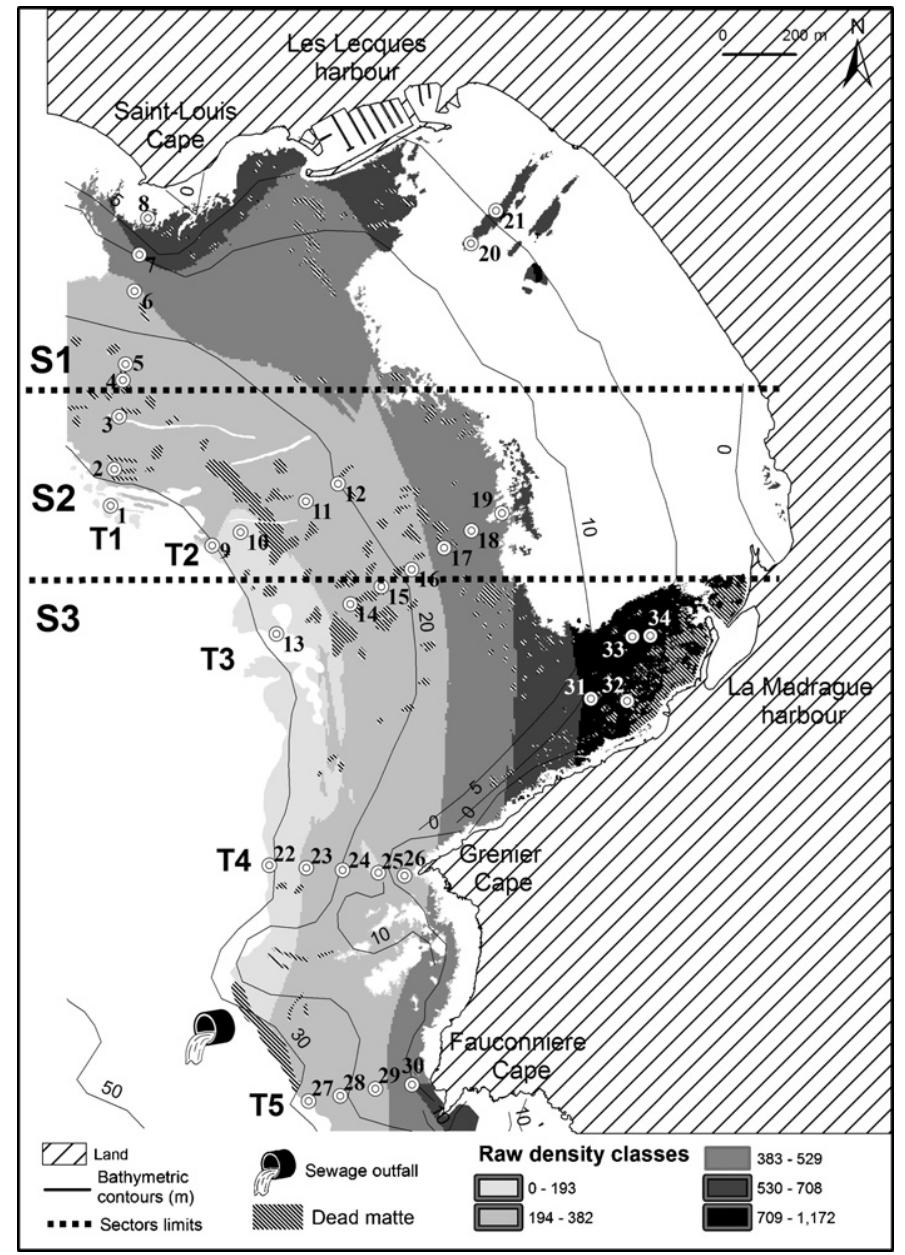

Fig. 1. Distribution of Posidonia oceanica and surface values of raw shoot density values (number $\mathrm{m}^{-2}$ ) as modelled by ordinary kriging. Sites where shoot density has been measured (double circle) from the transects $(\mathrm{T})$ of each sectors (S), are pointed out on the map. Jenks' natural breaks classification scheme was chosen for raw density classes' definition as it identifies break points by picking the class breaks that best group similar values and maximize the differences between classes.

semivariogram at the discontinuity at the origin) are equal or close to zero.

The ordinary kriging of raw data of shoot density (Fig. 1) confirms the existence of a marked gradient of shoot density values which follows the depth gradient. This gradient exists over the entire study area. Raw shoot density values are particularly high (530-1172 shoot $\left.\mathrm{m}^{-2}\right)$ along the north and south coasts $(0-10 \mathrm{~m}$ depth) and decrease with depth to $30 \mathrm{~m}$.

The result of ordinary kriging of Dn (Fig. 2) shows a different spatial pattern. The P. oceanica meadow of sector 1 (S1) is classified as high or very high density (Dn values between 0.1 and 0.5 and above 0.5 respectively, i.e. greater than the mean density). Sectors 2 (S2) and 3 (S3) are less homogenous. In areas shallower than $20 \mathrm{~m}$ depth, the entire meadow in S2 has high or very high values of Dn. Between 20 and $30 \mathrm{~m}$ depth, the meadow is classified as medium density (Dn values around zero, i.e. close to the mean density) and high density, with the exception of a patch of low density (Dn values between -0.5 and -0.1 , i.e. less than the mean density) around the biggest area of dead matte mapped in the study area (sites 10 and 11). Shallow meadow in the northern part of the $S 3$ (sites 31-34) is classified as high or very high density, as is the southern part of the sector (T5). An extensive oval-shaped area (oriented north-south) between 10 and $30 \mathrm{~m}$ depth has low and very low values of Dn. The southern limit of this area is located in the middle of a zone

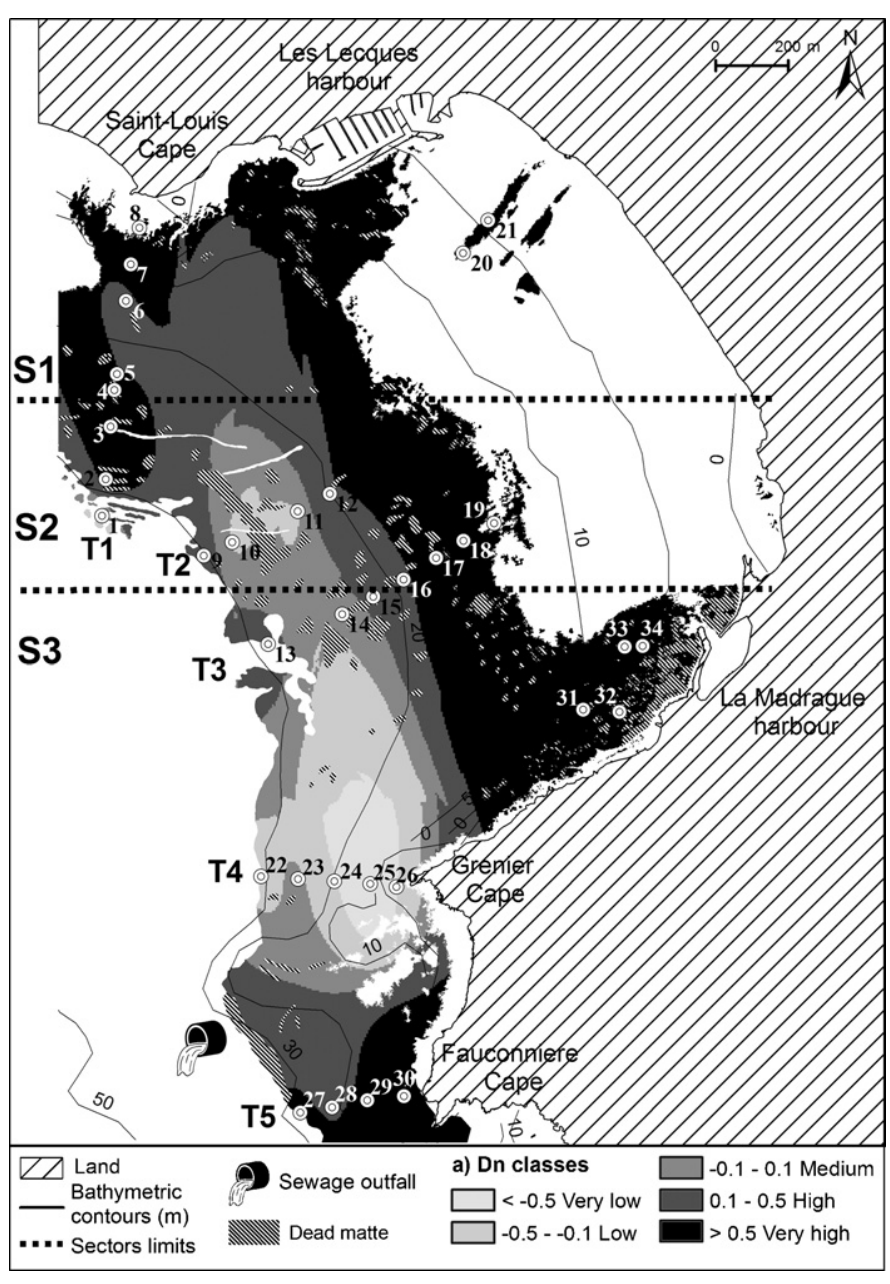

Fig. 2. Distribution of Posidonia oceanica in Saint-Cyr Bay and surface values of normalized shoot density (Dn) values as modelled by ordinary kriging. Sites where shoot density has been measured (double circle) from the transects (T) of each sectors $(S)$, are pointed out on the map.

that exhibits a lot of intermattes (between Grenier and Fauconniere Capes). The deep limit of the meadow in S3 is classified as medium to high density, with the exception of a small part around site 22 that has a low density.

\section{Discussion}

The method we propose here was able to eliminate depth effect and proved that the part of the density variation not explained by the depth parameter (46\% according to Pergent-Martini et al., 1999) is spatially structured (not a random phenomenon) and cannot be attributed to measurement errors or spatial sources of variation at distances smaller than the sampling interval (nugget value close to zero). The seeming persistence of a depth effect along transect $\mathrm{T} 3$ could suggest that the model of shoot density decline with depth from Pergent et al. (1995b) and Pergent-Martini et al. (1999) is not fully applicable at the present study site. However this is not supported by data from all other transects for which no pattern of decrease of shoot density with depth is observed. Results indicate that half of the meadow exhibits high or very high Dn values. We have to consider two different interpretations of these results. The first is that the method we present in this paper is correctly calibrated by Eq. (2), meaning that the P. oceanica meadow of the Saint-Cyr Bay is a particularly healthy ecosystem, at least in its Northern, Southern and shallower areas which has higher density 
values than the Mediterranean average. The second interpretation would be that Eq. (2) tends to underestimate the density values. Even if scientific scuba-divers described this $P$. oceanica meadow as in quite good condition (Bonhomme P., Bernard G., Cadiou G. pers. com.), it is clear that this new approach now needs to be tested and possibly recalibrated on a set of other sites across the Mediterranean coast.

This work shows that maps of normalized density of shoots (Dn) are more interesting than presence-absence or even raw shoot density interpolation maps. A normalized map highlights the information otherwise hidden by depth contained in raw shoot density data, and discriminates between healthy areas and potentially unhealthy seagrass patches. This new mapping approach shows great potential as a valuable tool to help investigate the possible causes for the meadow's condition. For the present study site for example, various natural or anthropic factors may be proposed to explain the remaining spatial structure of Dn and will need further investigation. The most obvious ones would be trawling and boat anchoring. The possible effects of the nearby sewage outfall on $P$. oceanica meadow health must also be considered. As the impacts of these two kinds of anthropic factors can be mitigated, it may be worthwhile using the technique described here to delimit areas where field sampling may be useful, and conservation policies should be undertaken.

This new approach is no more time consuming than the classical mapping methods, and it provides data of greater value and usefulness for seagrass meadows managers and other stakeholders.

\section{Acknowledgements}

The authors acknowledge with thanks the help of G. Bernard, P. Bonhomme, E. Charbonnel, G. Cadiou, L. Le Direac'h (GIS Posidonie) for diving assistance (data collection), G. Gascon, R. Quinquis (IFREMER) and P. Clabaut for scan side sonar assistance. They also acknowledge D. Kriticos from CSIRO Ecosystem Sciences and D. Vance from CSIRO Marine and Atmospheric Research for their valuable comments which improved the paper. This work was performed as part of a programme funded by the Conseil Régional PACA and the NGO Méditerranée 2000.

\section{References}

Augier, H., Boudouresque, C.F., 1973. Dix ans de recherches dans la zone marine du parc national de Port-Cros (France). Première partie. Ann. Soc. Sci. Nat. Archeol. Toulon Var. 25, 119-138.

Borg, J.A., Micallef, M.A., Schembri, P.J., 2006. Spatio-temporal variation in the structure of a deep water Posidonia oceanica meadow assessed using non-destructive techniques. Mar. Ecol. Prog. Ser. 27, 320-327.

Buia, M.C., Gambi, M.C., Zupo, V., 2000. Structure and functioning of Mediterranean seagrass ecosystems: an overview. Biol. Mar. Mediterr. 7, 167-190.

Cressie, N.A.C., 1991. Statistics for Spatial Data. J. Wiley, New York.

Duffy, J.E., 2006. Biodiversity and the functioning of seagrass ecosystems. Mar. Ecol. Prog. Ser. 311, 233-250.

Fornes, A., Basterretxea, G., Orfila, A., Jordi, A., Alvarez, A., Tintore, J., 2006. Mapping Posidonia oceanica from Ikonos. ISPRS J. Photogramm. Remote Sens. 60, 315-322.

Frederiksen, M., Krause-Jensen, D., Holmer, M., Laursen, J.S., 2004a. Long-term changes in area distribution of eelgrass (Zostera marina) in Danish coastal waters. Aquat. Bot. 78, 167-181.

Frederiksen, M., Krause-Jensen, D., Holmer, M., Laursen, J.S., 2004b. Spatial and temporal variation in eelgrass (Zostera marina) landscapes: influence of physical setting. Aquat. Bot. 78, 147-165.
Garono, R.J., Simenstad, C.A., Robinson, R., Ripley, H., 2004. Using high spatial resolution hyperspectral imagery to map intertidal habitat structure in hood canal, Washington, USA. Can. J. Remote Sens. 30, 54-63.

Gobert, S., Kyramarios, M., Lepoint, G., Pergent-Martini, C., Bouquegneau, J.M., 2003 Variations at different spatial scales of Posidonia oceanica (L.) Delile beds; effects on the physico-chemical parameters of the sediment. Oceanol. Acta 26, 199-207.

Leriche, A., Boudouresque, C.F., Bernard, G., Bonhomme, P., Denis, J., 2004. A onecentury suite of seagrass bed maps: can we trust ancient maps? Estuar. Coast. Shelf Sci. 59, 353-362.

Leriche, A., Pasqualini, V., Boudouresque, C.F., Bernard, G., Bonhomme, P., Clabaut, P. Denis, J., 2006. Spatial, temporal and structural variations of a Posidonia oceanica seagrass meadow facing human activities. Aquat. Bot. 84, 287-293.

Marcos-Diego, C., Bernard, G., García-Charton, J.A., Pérez-Ruzafa, À., 2000. Methods for studying impact on Posidonia oceanica meadows. In: Goñi (Ed.), Introduction Guide of Methods for Selected Ecological Studies in Marine Reserves. GIS Posidonie, Marseilles, pp. 57-62.

Montefalcone, M., Albertelli, G., Bianchi, C.N., Mariani, M., Morri, C., 2006. A new synthetic index and a protocol for monitoring the status of Posidonia oceanica meadows: a case study at Sanremo (Ligurian Sea, NW Mediterranean). Aquat. Conserv. Mar. Freshw. Ecosyst. 16, 29-42.

Panayotidis, P., Boudouresque, C.F., Marcot-Coqueugniot, J., 1981. Microstructure of Posidonia oceanica (Linnaeus) Delile beds. Bot. Mar. 24, 115-124.

Pasqualini, V., Pergent-Martini, C., Pergent, G., 1999. Environmental impact identification along the Corsican coast (Mediterranean sea) using image processing. Aquat. Bot. 65, 311-320.

Pergent, G., 1990. Utilisation de la technique de krigeage et cartographie benthique: intérêt et limites. Rapport Comm. Int. Mediterr. 32, 6.

Pergent, G., Barbier, J.C., Pergent-Martini, C., Soullard, M., 1995a. Microstructure de l'herbier à Posidonia oceanica de la baie de Calvi (Corse). Rapport Comm. Int. Mediterr. 34, 39.

Pergent, G., Pergent-Martini, C., 1988. Phenological study of Posidonia oceanica (Linnaeus) Delile around the Mediterranean sea. Ann. Inst. Oceanogr. 64, 79-100.

Pergent, G., Pergent-Martini, C., Boudouresque, C.F., 1995b. L'utilisation de l'herbier à Posidonia oceanica comme indicateur biologique de la qualité du milieu littora en Méditerranée: état des connaissances. Mésogée 54, 3-29.

Pergent-Martini, C., Leoni, V., Pasqualini, V., Ardizzone, G.D., Balestri, E., Bedini, R., Belluscio, A., Belsher, T., Borg, J., Boudouresque, C.F., Boumaza, S., Bouquegneau, J.M., Buia, M.C., Calvo, S., Cebrian, J., Charbonnel, E., Cinelli, F., Cossu, A., Di Maida G., Dural, B., Francour, P., Gobert, S., Lepoint, G., Meinesz, A., Molenaar, H., Mansour, H.M., Panayotidis, P., Peirano, A., Pergent, G., Piazzi, L., Pirrotta, M., Relini, G., Romero, J., Sanchez-Lizaso, J.L., Semroud, R., Shembri, P., Shili, A., Tomasello, A., Velimirov, B., 2005. Descriptors of Posidonia oceanica meadows: use and application. Ecol. Indic. 5, 213-230.

Pergent-Martini, C., Pasqualini, V., Ferrat, L., Pergent, G., 2006. Ecological data in integrated coastal zone management: case study of Posidonia oceanica meadows along the Corsican coastline (Mediterranean sea). Environ. Manage. 38, 889-895.

Pergent-Martini, C., Pergent, G., Fernandez, C., Ferrat, L., 1999. Value and use of Posidonia oceanica as a biological indicator. In: Medcoast, EMECS 99 Joint Conference , pp. 73-89.

Pirc, H., 1984. Depth-adaptation in Posidonia oceanica (L.) Delile. In: Internationa workshop on Posidonia oceanic beds, Gis Posidonie, Marseilles, pp. 227-234.

Ruiz, J.M., Romero, J., 2001. Effects of in situ experimental shading on the Mediterranean seagrass Posidonia oceanica. Mar. Ecol. Prog. Ser. 215, 107-120.

Scardi, M., Chessa, L.A., Fresi, E., Pais, A., Serra, S., 2006. Optimizing interpolation of shoot density data from a Posidonia oceanica seagrass bed. Mar. Ecol. Evol. Persp. 27, 339-349.

Scardi, M., Fresi, E., Ardizzone, G.D., 1989. Cartographic representation of seagrass beds: application of a stochastic interpolation technique (kriging). In: International Workshop on Posidonia oceanic Beds 2, GIS Posidonie, Marseilles, pp. 19-27.

Ward, D.H., Morton, A., Tibbitts, T.L., Douglas, D.C., Carrera-Gonzalez, E., 2003. Long-term change in eelgrass distribution at Bahia San Quintin, Baja California Mexico, using satellite imagery. Estuaries 26, 1529-1539.

Webster, R., Oliver, M.A., Margaret, A., 2007. Geostatistics for Environmental Scientists. Wiley, Chichester.

Zimmerman, R.C., Cabello-Pasini, A., Alberte, R.S., 1994. Modeling daily production of aquatic macrophytes from irradiance measurements-a comparative analysis. Mar. Ecol. Prog. Ser. 114, 185-196.

Zupo, V., Buia, M.C., Gambi, M.C., Lorenti, M., Procaccini, G., 2006a. Temporal variations in the spatial distribution of shoot density in a Posidonia oceanica meadow and patterns of genetic diversity. Mar. Ecol. 27, 328-338.

Zupo, V., Mazzella, L., Buia, M.C., Gambi, M.C., Lorenti, M., Scipione, M.B., Cancemi G., 2006b. A small-scale analysis of the spatial structure of a Posidonia oceanica meadow off the Island of Ischia (Gulf of Naples, Italy): relationship with the seafloor morphology. Aquat. Bot. 84, 101-109. 